\title{
CARACTERIZAÇÃO FENOLÓGICA E REQUERIMENTO TÉRMICO DA CULTIVAR MOSCATO GIALLO SOB COBERTURA PLÁSTICA ${ }^{1}$
}

\author{
GERALDOCHAVARRIA ${ }^{2}$, HENRIQUE PESSOA DOS SANTOS ${ }^{3}$, FRANCISCO MANDELLI $^{4}$, \\ GILMAR ARDUÍNO BETTIO MARODIN ${ }^{5}$, HOMERO BERGAMASCHI $^{6}$, LOANA SILVEIRACARDOSO $^{7}$
}

RESUMO - Os efeitos da cobertura plástica (CP) sobre a fenologia e o requerimento térmico da Vitis vinifera L. 'Moscato Giallo' foram estudados em dois ciclos (2005/2006 e 2006/2007). Determinou-se a duração média dos principais períodos fenológicos por meio de avaliações semanais, desde a poda até a queda das folhas. O somatório térmico em graus-dia acumulados (GD) foi calculado considerando-se a temperatura-base de $10^{\circ} \mathrm{C}$, e medidas da temperatura do ar máxima e mínima ao longo de todo o ciclo, nas áreas coberta e descoberta (testemunha). A cobertura plástica aumentou o somatório térmico e antecipou o início da brotação, reduzindo a duração das etapas fenológicas da poda até a mudança de cor das bagas. Entretanto, a redução da radiação fotossinteticamente ativa (RFA) proporcionada pela cobertura plástica atrasou, em média, 18 dias o processo de maturação das uvas da cultivar Moscato Giallo. A soma térmica acumulada (poda até colheita) das áreas coberta e descoberta foi, respectivamente, 2.079 e 1.847 GD no primeiro ciclo, e 1.864 e 1.640 GD no segundo ciclo. A cobertura plástica exige uma alteração nas práticas culturais, como a necessidade de poda verde para reduzir os efeitos da restrição de RFA e o atraso na data de colheita, em relação ao cultivo convencional, em função da menor taxa de evolução da maturação sob a cobertura.

Termos para indexação: videira, cultivo protegido, microclima, fenologia, graus-dia.

\section{PHENOLOGICAL CHARACTERIZATIONAND THERMAL REQUIREMENT OF MOSCATO GIALLO CULTIVAR UNDER PLASTIC COVER}

\begin{abstract}
The plastic overhead cover (POC) effects on phenology and thermal requirement of grapevine Vitis vinifera L. 'Moscato Giallo' were evaluated in two seasons (2005/2006 and 2006/2007). The phenology was weekly determined since the winter pruning until the falling of the leaves. The thermal requirement as degree-days $\left(\mathrm{GD}^{\circ} \mathrm{C}\right)$ was calculated in the same period using $10^{\circ} \mathrm{C}$ as base temperature and measured of maximal and minimal air temperature throughout both cycles in covered and uncovered areas. POC increased the thermal sum and it anticipated the budburst and decreased the duration of phenological phases from the winter pruning until the changing of the colors of the berries. However, the POC restricted the photosynthetically active radiation (PAR) and it reduced in 18 days the ripening process of grapes, in relation to uncovered plants. The thermal sum accumulated (pruning to harvest) under covered and uncovered areas was respectively, 2079 and $1864 \mathrm{GD}^{\circ} \mathrm{C}$ in the first cycle, and 1847 and $1640 \mathrm{GD}^{\circ} \mathrm{C}$ in the second cycle. POC demands alterations in vineyard management such as the green pruning (aiming to reduce the effect of PAR restriction) and the delay in harvest date due to lower ripening under POC, in comparison to uncovered cultivation.
\end{abstract}

Index terms: grapevine, plastic overhead cover, microclimate, phenology, degree-days.

\footnotetext{
'(Trabalho 098-08). Recebido em: 15-04-2008. Aceito para publicação em: 09-12-2008.

${ }^{2}$ Eng. Agr ${ }^{\circ}$ M. Sc. Doutorando Universidade Federal do Rio Grande do Sul, Departamento de Horticultura e Silvicultura, CEP 91540-000, Porto Alegre-RS. e-mail: geraldochavarria@hotmail.com, Bolsista: CNPq

${ }^{3}$ Eng. Agr ${ }^{\circ}$ Dr. Pesquisador Embrapa Uva e Vinho, CEP 95700-000, Bento Gonçalves-RS., e-mail: henrique@cnpuv.embrapa.br ${ }^{4}$ Eng. Agr ${ }^{\circ}$ Dr. Pesquisador Embrapa Uva e Vinho, CEP 95700-000, Bento Gonçalves-RS., e-mail: mandelli@cnpuv.embrapa.br ${ }^{5}$ Eng. Agr ${ }^{\circ}$ Professor Dr. Departamento de Horticultura, Universidade Federal do Rio Grande do Sul, CEP 91540-000, Porto Alegre-RS. e-mail: marodin@ufrgs.br

${ }^{6}$ Eng. Agr ${ }^{\circ}$ Professor Dr. Departamento de Agrometeorologia, Universidade Federal do Rio Grande do Sul, CEP 91540-000, Porto Alegre-RS. e-mail: homerobe@ufrgs.br

${ }^{7}$ Eng. Agr ${ }^{\circ}$ Doutoranda Universidade Federal do Rio Grande do Sul, Departamento de Agrometeorologia e Forrageiras, CEP 91540-000, Porto Alegre-RS. e-mail: loanacar@yahoo.com.br
} 


\section{INTRODUÇÃO}

A área com cultivo protegido de videiras destinadas à vinificação vem crescendo à medida que se avança no conhecimento das vantagens relacionadas aos aspectos fitossanitários, devido à redução de fungicidas e aos aspectos enológicos, em função da melhoria na qualidade do mosto (Chavarria et al., 2007b). Entretanto, diversos fatores relacionados ao cultivo da videira sob cobertura plástica ainda carecem de estudos, principalmente aqueles relacionados às respostas fisiológicas nas condições microclimáticas impostas por essa tecnologia.

A fenologia da videira tem sido amplamente estudada em cultivos convencionais no Brasil (Mandelli, 1984; Leão \& Da Silva, 2003), sendo a caracterização da duração das fases fenológicas diretamente relacionada ao clima da região. Esta análise também se apresenta como ferramenta importante na interpretação da interação da cultura com a condição de microclima em que o vinhedo se situa (Terra et al., 1998). A caracterização fenológica e térmica é imprescindível para a programação de práticas culturais, irrigação, colheita e utilização de produtos químicos para o controle de pragas e doenças (Mullins et al., 1992).

O microclima da videira pode ser modificado substancialmente em função da cobertura plástica, principalmente com aumento de temperatura e redução de radiação solar (Chavarria et al., 2007a). Consequentemente, estas modificações podem interferir no desenvolvimento fenológico e produtivo da videira, com influência direta na conversão da energia solar em carboidratos (fotossíntese) e na distribuição/utilização de carbono pelos diferentes órgãos da planta, definindo seu potencial de produção (Palchetti et al., 1995). O uso de índices bioclimáticos em regiões ou sistemas de produção, para os quais não foram estabelecidos, pode gerar, entretanto, informações errôneas do comportamento da videira em uma determinada condição (Mandelli, 1984). De tal forma, os estudos para estabelecer relações entre o comportamento da cultura e os fatores ambientais são essencias para o êxito do cultivo protegido de videira.

O objetivo deste trabalho foi caracterizar a fenologia e o requerimento térmico da videira Vitis vinifera L., cv. Moscato Giallo sob cobertura plástica, nas condições da Serra Gaúcha.

\section{MATERIAL E MÉTODOS}

O experimento foi realizado em um vinhedo comercial localizado em Flores da Cunha-RS (29 06'S e $51^{\circ} 20^{\prime} \mathrm{O}$ e $541 \mathrm{~m}$ de altitude), durante os ciclos de 2005/2006 e 2006/2007. Foram utilizadas plantas de videira (Vitis vinifera L.), de oito anos de idade, da cv. Moscato Giallo (clone VCR1), enxertadas sobre o porta-enxerto Kober 5BB e plantadas com distâncias de 3,0 m entre linhas e 0,9 m entre plantas. As linhas de plantio direcionavam-se no sentido sudeste-noroeste, sendo a condução em "Y", com poda mista, utilizando-se em média de quatro varas de 6-8 gemas e oito esporões de duas gemas por planta.

$\mathrm{O}$ vinhedo foi dividido aleatoriamente em duas partes, sendo uma das partes com 12 fileiras cobertas na linha de cultivo, em julho de 2005, com lonas plásticas trançadas, transparentes, impermeabilizadas com polietileno de baixa densidade, com $160 \mu \mathrm{m}$ de espessura e largura de $2,65 \mathrm{~m}$. Na outra parte, foram mantidas cinco fileiras descobertas, cujas linhas centrais foram consideradas como plantas-controle. As coberturas ficaram a uma altura de $\pm 100 \mathrm{~cm}$, em relação à posição central do dossel vegetativo, e $\pm 20 \mathrm{~cm}$ em cada extremidade, constituindo um $\mathrm{V}$ invertido sobre um dossel em Y. Destaca-se que as coberturas não foram retiradas no intervalo entre os dois ciclos.

Em cada área (sob a cobertura plástica e a céu aberto), foram selecionadas aleatoriamente e avaliadas 10 plantas. Esta seleção seguiu um delineamento experimental de blocos inteiramente casualizados, considerando cada planta uma unidade experimental. O principal parâmetro considerado para o bloqueamento foi a declividade do terreno (10\%).

As avaliações visuais da fenologia foram feitas semanalmente da poda de inverno $\left(1^{\circ} \mathrm{de}\right.$ setembro de 2005 e 17 de agosto de 2007, para os ciclos de 2005/06 e 2006/07, respectivamente) até a queda das folhas (26-06-06 e 24-04-06 para os cultivos coberto e descoberto, respectivamente, no ciclo de 2005/06; 31-05-07 e 30-04-07 para os cultivos coberto e descoberto, respectivamente, no ciclo de 2006/07). A determinação das fases fenológicas foi efetuada por meio da escala proposta por Lorenz et al. (1995), dividida nos seguintes subperíodos: Estádio 0 (poda - ponta verde); Estádio 1 (início da brotação - 5 a 6 folhas separadas e inflorescência visível); Estádio 5 (inflorescência alongada inflorescência desenvolvida); Estádio 6 (início de floração - plena floração); Estádio 7 (frutificação ervilha); Estádio 8 (início da maturação - plena maturação); Estádio 9 (início da queda das folhas - 
final da queda das folhas). As colheitas das uvas, nas duas áreas (coberta e descoberta), foram realizadas em 02-03-06 e 22-02-07, correspondentes às safras de 2006 e 2007, respectivamente.

O microclima foi avaliado por meio das medições de temperatura e umidade relativa do ar (psicrômetros não aspirados de pares termoelétricos); velocidade do vento (anemômetro de conchas) e radiação fotossinteticamente ativa (400-700 nm, barras de 1,20 m equipadas com cinco células fotovoltaicas ligadas em série), nas áreas com e sem cobertura plástica, sendo instalados dois conjuntos de sensores, acima do dossel vegetativo e ao nível dos cachos. Todos os sensores da área experimental foram conectados a sistemas de aquisição de dados (CR10 e CR21X, Campbell Scientific Inc. $\left.{ }^{\circledR}\right)$. Ambos os sistemas foram programados para efetuar leituras a cada minuto e armazenar médias a cada 30 minutos.

Para o cálculo da soma dos graus-dia (GD), empregou-se o modelo proposto por Villa Nova et al. (1972), utilizando-se das temperaturas ocorridas em ambas as áreas, entre a poda hibernal e a colheita, considerando a temperatura-base de $10^{\circ} \mathrm{C}$, de acordo com Santos et al. (2007). Foram utilizadas as seguintes equações: GD $=(\mathrm{Tm}-\mathrm{Tb})+(\mathrm{TM}-\mathrm{Tm}) / 2$, para $\mathrm{Tm}>\mathrm{Tb} ; \mathrm{GD}=(\mathrm{Tm}-\mathrm{Tb})^{2} / 2(\mathrm{TM}-\mathrm{Tm})$, para $\mathrm{Tm}<\mathrm{Tb} ; \mathrm{GD}=0$ para $\mathrm{Tb}>\mathrm{TM}$, sendo $\mathrm{Tm}$ : Temperatura mínima; Tb: Temperatura-base e TM: Temperatura máxima.

$\mathrm{Na}$ análise estatística dos parâmetros microclimáticos, utilizou-se o programa $R(R, 2007)$, sendo que os dados de microclima (temperatura do ar média, mínima e máxima; umidade relativa do ar; radiação fotossinteticamente ativa e velocidade do vento) foram pareados, e as diferenças entre ambos os tratamentos foram analisadas por regressão linear em função da área descoberta. A significância do coeficiente angular das equações resultantes foi avaliada pelo Teste $\mathrm{t}$. $\mathrm{Na}$ análise dos dados de radiação e velocidade do vento, o intercepto foi fixado em zero, pois quando a medida externa for nula, a interna deve também ser obrigatoriamente nula. As variáveis de duração dos subperíodos fenológicos e acúmulo de graus-dia foram submetidas à análise da variância, e as médias, comparadas pelo Teste de Tukey, a 5\% de probabilidade.

\section{RESULTADOS E DISCUSSÃO}

A cobertura plástica proporcionou uma diferenciação no microclima da videira em comparação ao cultivo descoberto (Tabela 1 ). Com relação à temperatura, as máximas diárias foram as que mais sofreram influência. Isso pode ser verificado pelo coeficiente angular de regressão, que foi altamente significativo $(\mathrm{P}=0,0005)$, indicando que, para cada $1,0^{\circ} \mathrm{C}$ de variação na temperatura externa, sob a cobertura, a temperatura variou $0,9^{\circ} \mathrm{C}$ (Tabela 1$)$. As temperaturas mínima e média tiveram comportamento similar, porém bem menor no coeficiente angular de regressão, indicando uma alteração aproximada de $1,0^{\circ} \mathrm{C}$ sob a cobertura, para cada $1,0^{\circ} \mathrm{C}$ de variação na temperatura externa (Tabela 1).

A temperatura é, indubitavelmente, um fator limitante para a brotação da videira (Mandelli, 2002). No presente trabalho, os resultados distintos do aumento de temperatura em cada área mostraram incremento diferenciado no acúmulo térmico (GD), com somatório de 2.079 e 1.864 GD sob a cobertura plástica e de 1.847 e 1.640 GD na testemunha, para os ciclos de 2005/2006 e 2006/2007, respectivamente (Tabela 2). Este contraste térmico resultou na antecipação da brotação (subperíodo 1) das plantas cultivadas sob a cobertura plástica (Figura 1).

O percentual de brotação foi similar em ambos os tratamentos (acima de 70\% nas áreas coberta e descoberta, nos dois ciclos avaliados), mostrando que o aumento da temperatura não afetou a superação da dormência na área coberta, haja vista que a videira apresenta poucas restrições à necessidade de frio (Westphalen, 1977). Além disso, a cobertura plástica não afetou as temperaturas mínimas (Tabela 1). Entretanto, alguns autores consideram que temperaturas mais elevadas podem interferir na superação do repouso hibernal em fruteiras de clima temperado (Couvillon \& Erez, 1985), embora a videira apresente características distintas das demais espécies temperadas.

$\mathrm{Na}$ avaliação do número de dias e da quantidade de graus-dia necessários para a ocorrência dos diversos períodos de desenvolvimento da videira 'Moscato Giallo', observou-se que, em função do maior acúmulo de calor proporcionado pela cobertura plástica, na maioria dos subperíodos iniciais $(0 ; 1$ e 5$)$, houve, nos dois ciclos, diminuição no número de dias necessários para a videira completar esses períodos (Tabela 2). No ciclo de 2005/06, a duração do período da poda até $70 \%$ em ponta verde (subperíodo 0) foi de 32 e 37 dias (Tabela 2), respectivamente, para 
plantas sob a cobertura plástica e testemunha. Contudo, no ciclo seguinte, este subperíodo não diferiu do cultivo convencional, tendo a cobertura um efeito estimulatório da brotação somente no subperíodo 1. De maneira geral, destaca-se que a cobertura plástica antecipa a brotação e encurta os subperíodos fenológicos até o início da maturação (Figura 1). Considerando-se desde a poda à presença de brotações com 5 - 6 folhas e inflorescência visível, ou seja, do subperíodo 0 ao 1, as videiras cobertas tiveram estes períodos inferiores em duas semanas, se comparado às videiras descobertas (Figura 1).

Todavia, nos subperíodos 6 e 7, referentes ao início de floração e grão de ervilha, não foram observadas diferenças entre os cultivos, com e sem cobertura plástica, o que aponta que o aumento das temperaturas provocado pela cobertura, nestes períodos, não apresentou significância (Tabela 2 e Figura 1). Isto demonstra que a maior influência da cobertura no período de floração pode ocorrer pela restrição da chuva sobre as flores, podendo auxiliar no pegamento dos frutos em épocas chuvosas. Contudo, nos dois ciclos avaliados, não foram observadas precipitações pluviométricas capazes de afetar a floração e, consequentemente, salientar este benefício.

O período fenológico que apresentou maior número de dias, nos dois sistemas de produção investigados, foi o de maturação das bagas, sobretudo da uva com cobertura plástica (Tabela 2). Isto pode proporcionar uma melhora na qualidade da uva, tendo em vista que o fruto fica por mais tempo na planta, havendo condições de aumentar açúcares e outros compostos fenólicos e aromáticos, podendo reverter-se em um diferencial favorável para a comercialização do produto (Jackson, 2000). Neste período, durante os dois ciclos, as temperaturas máximas do vinhedo coberto foram superiores às do cultivo descoberto (Figura 2).

Diferentes resultados também foram observados de um ciclo para o outro na diminuição da radiação RFA, no nível dos cachos, onde, no segundo ciclo, possivelmente devido à uma poda verde mais severa, os cachos ficaram mais expostos à radiação (Figura 2).

A energia solar tem efeito direto sobre a maturação das bagas (Smart \& Robinson, 1985), já que a concentração de açúcares e ácidos é dependente do acúmulo de temperatura e de seus níveis (Mullins et al., 1992). Conforme apresentado anteriormente, após o período de início de brotação até a mudança de cor da baga, começo da maturação, a temperatura apresentou-se como o fator determinante para a antecipação das fases fenológicas (Tabela 2). Todavia, nos dois ciclos, após o início da maturação, a radiação começa a ter influência mais decisiva, a qual pode ser observada pelo prolongamento do período de maturação na área coberta. A radiação fotossinteticamente ativa sob a cobertura sofreu redução linear de $37 \%$ ( $\mathrm{P}<$ 0,0001). O efeito da cobertura variou de um ciclo para outro, tendo redução de $33 \%$ no primeiro ciclo e $44 \%$ no segundo ciclo, o que está relacionado à perda de transparência do plástico ao longo do tempo (Tabela 1). A redução de radiação ao nível das folhas, observada neste trabalho, corrobora o que foi observado por Rana et al. (2004). Os autores avaliaram o efeito da cobertura plástica no microclima da videira da cv. Itália; contudo, neste estudo, não foi avaliada a redução da radiação próxima aos cachos. $\mathrm{Na}$ avaliação da incidência de radiação fotossinteticamente ativa no nível dos cachos do presente trabalho, foi observado um decréscimo de radiação de $56 \%$ e $24 \%$, respectivamente, para os ciclos de 2005/06 e 2006/ 07. Esta diferença entre os dois ciclos ocorreu em função de uma poda verde e desfolha mais severa no segundo ciclo.

No microclima formado pela ação da cobertura plástica, observou-se que a umidade relativa do ar foi o parâmetro que teve menor variação em relação ao ambiente externo, sendo que, nos cachos, a umidade relativa média foi apenas 0,7 u.p. maior do que a externa $(\mathrm{P}<0,0001)$ (Tabela 1$)$. Entretanto, a cobertura plástica diminui a água livre sobre as folhas e cachos, o que exerce grande influência na incidência e severidade de doenças fúngicas no vinhedo, assim como reduz também o efeito do vento e da chuva (Chavarria et al., 2007b). Em função disto, as folhas sob a cobertura plástica permaneceram biologicamente ativas por mais 21 dias, se comparadas às plantas no cultivo convencional, no primeiro ano de estudo.

Desta forma, destaca-se que a abscisão das folhas sob cobertura plástica ocorre, principalmente, por senescência natural, sem nenhuma interfência externa (biológica, física e/ou química). Distintamente da condição convencional, onde a queda precoce das folhas ocorre sobretudo devido ao ataque de moléstias fúngicas ou respostas de fitotoxidade devido a produtos fitossanitários aplicados. Este comportamento propicia um prolongamento do processo fotossintético das plantas sob cobertura plástica, podendo, com isso, acumular mais carbono. Isto é importante, pois quantidades maiores de reservas de carbono podem contribuir para a fertilidade das gemas e, consequentemente, para o potencial produtivo da 
planta (Mullins et al., 1992). Entretanto, no segundo ciclo avaliado, as folhas das plantas sob cobertura plástica tiveram uma queda mais precoce (-14 dias em relação ao ciclo anterior) em função de um ataque severo de míldio (Plasmopara viticola) ocasionado pela água livre provinda de neblinas com ventos laterais e pela ausência de tratamentos químicos nesta área. Apesar de não repetir o que foi observado no primeiro ciclo, este resultado salienta o impacto que a ação biológica exerce sobre a vida útil da folha. Além disso, expõe que o manejo fitossanitário da área coberta deve ser ajustado conforme a presença de água livre e a ocorrência de focos de doença, de acordo com o abordado por Chavarria et al. (2007b).

Como foi observado neste trabalho, a temperatura e a radiação fotossinteticamente ativa atuam como fatores determinantes sobre a duração das fases fenológicas, que possibilitam ao produtor realizar um manejo diferenciado do vinhedo conduzido sob cobertura plástica. Isso pode permitir a obtenção de uvas em épocas distintas, de acordo com as necessidades de mercado, e elevar os preços de venda devido à melhoria na qualidade dos frutos. Sendo assim, se a cobertura plástica for instalada logo após a poda de inverno, o plástico terá efeito estimulante sobre a brotação e o crescimento vegetativo, como pode ser observado na Figura 1. Em contrapartida, se instalado no começo da maturação, seu efeito inverte-se, fazendo com que o processo de maturação, seja prolongado, em comparação ao cultivo convencional da videira (Figura 1).

Porém, quando o plástico for utilizado durante todo o ciclo, pode-se observar que a precocidade obtida no princípio da brotação até a mudança de cor é perdida na fase de maturação (Tabela 2). Este fato foi constatado por Antonacci (1993), que estudou uvas de mesa por um período de 10 anos, concluindo que é possível antecipar em 10 dias o início da brotação quando a cobertura for instalada cerca de um mês antes do previsto para o começo desta fase fenológica, também obtendo-se antecipação de 19 dias da colheita. Para esta anticipação, é necessária a ocorrência de temperaturas superiores a $30^{\circ} \mathrm{C}$ na fase de floração, de forma a não comprometer a polinização. Contudo, o autor não observou interferência da cobertura no atraso da maturação. Possivelmente, este resultado esteja associado às cultivares estudadas, de forma que a cobertura apresentou maior efeito sobre a antecipação da brotação e menor sobre a maturação das uvas.

Desta maneira, é possível sugerir diferentes comportamentos das cultivares sob cobertura plástica, tanto para as espécies Vitis vinifera como para Vitis labrusca. Schiedeck (1996), que estudou o efeito de estufas na fenologia da cultivar Niágara Rosada (Vitis labrusca), observou antecipação média de 20 dias entre a poda e o momento onde o mosto alcançou $15^{\circ}$ Brix, comparativamente à culturatestemunha conduzida a céu aberto. $O$ experimento demonstrou que esta antecipação se sucedeu de forma crescente ao longo do ciclo da videira estudada. A cultura sob cobertura plástica teve uma evolução da maturação das bagas mais rápida; possivelmente, isto proporcionou preços mais compensatórios da fruta no mercado.

TABELA 1- Médias das observações microclimáticas em vinhedo da cultivar Moscato Giallo conduzida em "Y", com cobertura plástica (C) e descoberta (D), no ciclo de 2005/06 e 2006/07. Flores da Cunha-RS.

\begin{tabular}{|c|c|c|c|c|c|}
\hline \multirow{2}{*}{ Variáveis microclimáticas } & \multicolumn{2}{|c|}{$2005 / 2006$} & \multicolumn{2}{|c|}{$2006 / 2007$} & \multirow{2}{*}{ Equações de regressão } \\
\hline & Coberta & Descoberta & Coberta & Descoberta & \\
\hline Tmáx. dossel $\left({ }^{\circ} \mathrm{C}\right)$ & 31,9 & 28,1 & 31,8 & 30,3 & $\mathrm{C}=4,51+0,897 \mathrm{D} \quad(\mathrm{P}=0,0005)^{* *}$ \\
\hline Tmédia dossel $\left({ }^{\circ} \mathrm{C}\right)$ & 21,2 & 20,2 & 21,9 & 21,8 & $\mathrm{C}=1,37+0,960 \mathrm{D} \quad(\mathrm{P}=0,0265)$ \\
\hline Tmín. dossel $\left({ }^{\circ} \mathrm{C}\right)$ & 14,7 & 14,5 & 16,3 & 16,0 & $\mathrm{C}=0,64+0,972 \mathrm{D} \quad(\mathrm{P}=0,0012)$ \\
\hline Umidade relativa do dossel $(\%)$ & 83,2 & 82,5 & $*$ & $*$ & $\mathrm{C}=13,2+0,848 \mathrm{D} \quad(\mathrm{P}<0,0001)$ \\
\hline Radiação fotossint. ativa (MJ.m² ${ }^{-2} \cdot$ iia $\left.^{-1}\right)$ & 5,38 & 7,98 & 4,32 & 7,63 & $\mathrm{C}=0,629 \mathrm{D} \quad(\mathrm{P}<0,0001)$ \\
\hline Velocidade do vento diária $\left(\mathrm{m}_{\mathrm{s}} \mathrm{s}^{-1}\right)$ & 0,09 & 0,904 & 0,08 & 0,82 & $(\mathrm{P}<0,0001)$ \\
\hline
\end{tabular}

* ausência de dados devido a problemas nos sensores termopares de bulbo úmido.

**probabilidade de o coeficiente angular ser igual a 1 (não haver diferença entre coberto e descoberto), pelo Teste t. 
TABELA 2- Número de dias e requerimento térmico (GD) nos respectivos estádios fenológicos da 'Moscato Giallo' cultivada sob cobertura plástica (C) e em cultivo convencional (D), nos ciclos de 2005/ 06 e 2006/07. Flores da Cunha-RS.

\begin{tabular}{|c|c|c|c|c|c|c|c|c|}
\hline \multirow{3}{*}{$\begin{array}{c}\text { Estádio } \\
\text { fenológico* }\end{array}$} & \multicolumn{4}{|c|}{ Ciclo 2005/06 } & \multicolumn{4}{|c|}{ Ciclo 2006/07 } \\
\hline & \multicolumn{2}{|c|}{ Dias } & \multicolumn{2}{|c|}{ Graus-dia (GD) } & \multicolumn{2}{|c|}{ Dias } & \multicolumn{2}{|c|}{ Graus-dia (GD) } \\
\hline & $\mathrm{C}$ & $\mathrm{D}$ & $\mathrm{C}$ & $\mathrm{D}$ & $\mathrm{C}$ & $\mathrm{D}$ & $\mathrm{C}$ & $\mathrm{D}$ \\
\hline 0 & $32 \mathrm{bA}^{* *} *$ & $37 \mathrm{aA}$ & $205 \mathrm{bA}$ & $222 \mathrm{aA}$ & $28 \mathrm{aB}$ & $25 \mathrm{aB}$ & $111 \mathrm{aA}$ & $103 \mathrm{aB}$ \\
\hline 1 & $20 \mathrm{bA}$ & $25 \mathrm{aA}$ & $197 \mathrm{aA}$ & $219 \mathrm{aA}$ & $15 \mathrm{bB}$ & $27 \mathrm{aA}$ & $56 \mathrm{bB}$ & $151 \mathrm{aB}$ \\
\hline 5 & $13 \mathrm{bA}$ & $17 \mathrm{aA}$ & $115 \mathrm{bA}$ & $174 \mathrm{aA}$ & $12 \mathrm{bA}$ & $17 \mathrm{aA}$ & $116 \mathrm{aA}$ & $123 \mathrm{aB}$ \\
\hline 6 & $21 \mathrm{aA}$ & $21 \mathrm{aA}$ & $270 \mathrm{aA}$ & $230 \mathrm{bA}$ & $18 \mathrm{aA}$ & $15 \mathrm{aB}$ & $218 \mathrm{aB}$ & $175 \mathrm{bB}$ \\
\hline 7 & $32 \mathrm{aA}$ & $34 \mathrm{aA}$ & $410 \mathrm{bA}$ & $465 \mathrm{aA}$ & $22 \mathrm{aB}$ & $21 \mathrm{aB}$ & 191bB & $177 \mathrm{aB}$ \\
\hline 8 & $56 \mathrm{bB}$ & $40 \mathrm{aB}$ & $882 \mathrm{aB}$ & $537 \mathrm{bB}$ & $86 a A$ & $68 \mathrm{bA}$ & $1172 \mathrm{aA}$ & $911 \mathrm{bA}$ \\
\hline 9 & $102 \mathrm{aA}$ & $81 \mathrm{bA}$ & $* * *$ & $* * *$ & $85 \mathrm{aB}$ & $78 \mathrm{bA}$ & $* * *$ & $* * *$ \\
\hline Poda-colheita & $174 \mathrm{aB}$ & $174 \mathrm{aA}$ & $2079 \mathrm{aA}$ & $1847 \mathrm{bA}$ & $188 \mathrm{aA}$ & $178 \mathrm{bA}$ & $1864 \mathrm{aB}$ & $1640 \mathrm{bB}$ \\
\hline
\end{tabular}

*A determinação dos períodos fenológicos foi efetuada por meio da escala proposta por Lorenz et al. (1995), dividida nos seguintes subperíodos: Estádio 0 (poda - ponta verde); Estádio 1 (início da brotação - 5 a 6 folhas separadas e inflorescência visível); Estádio 5 (inflorescência alongada - inflorescência desenvolvida); Estádio 6 (início de floração - plena floração); Estádio 7 (frutificação - ervilha); Estádio 8 (início da maturação - plena maturação); Estádio 9 (início da queda das folhas - queda das folhas); **dados médios na linha, seguida de letras minúsculas e maiúsculas, diferem entre si ao grau de significância de 5\%, pelo teste de Tukey, separadamente para dias, em cada estádio fenológico e graus-dia; ***não foram computados o acúmulo de graus-dia no período de início à queda das folhas.

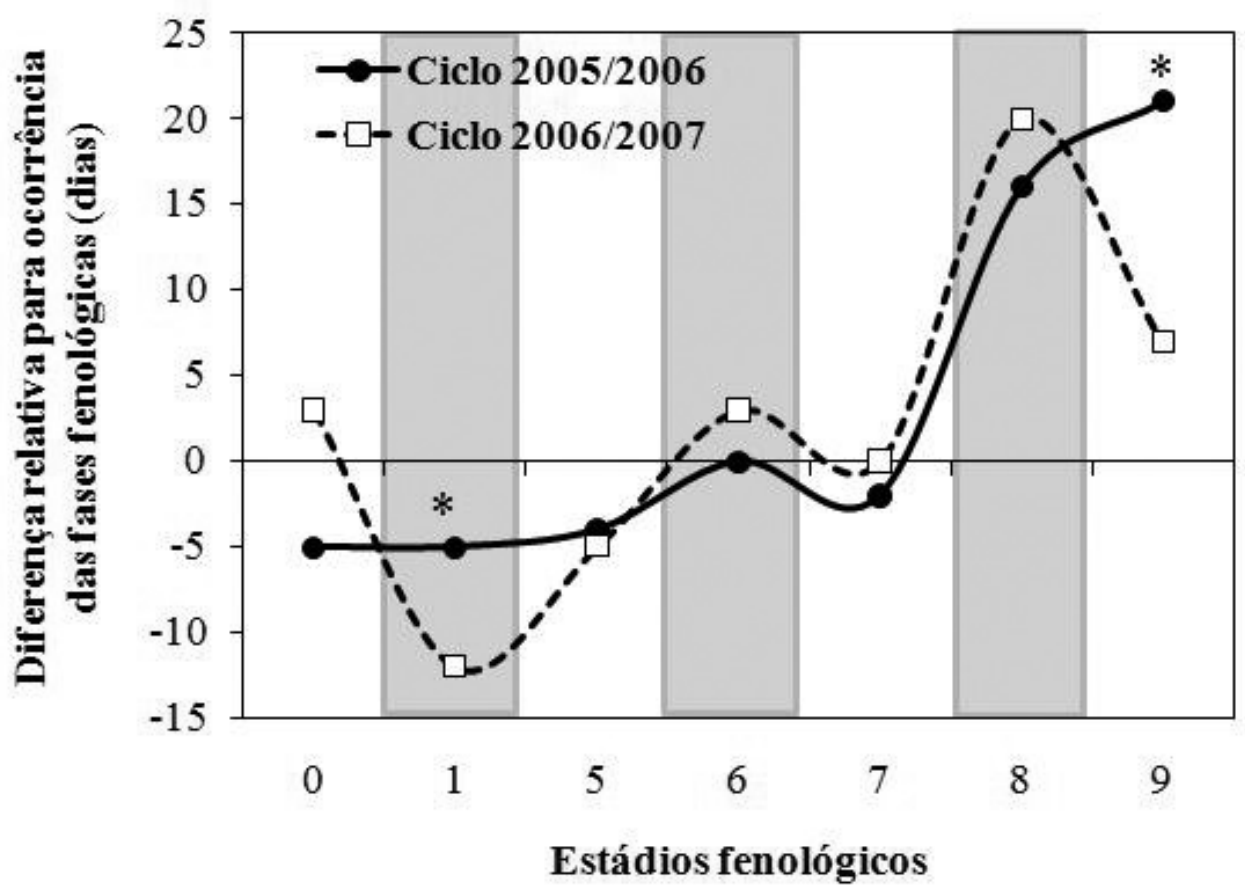

FIGURA 1- Interfência da cobertura plástica sobre o subperíodos fenológicos da cultivar Moscato Giallo em relação ao cultivo convencional, nos ciclos de 2005/06 e 2006/07. A determinação dos períodos fenológicos foi efetuada através da escala proposta por Lorenz et al. (1995), dividida nos seguintes subperíodos: Estádio 0 (poda - ponta verde); Estádio 1 (início da brotação - 5 a 6 folhas separadas e inflorescência visível); Estádio 5 (inflorescência alongada - inflorescência desenvolvida); Estádio 6 (início de floração - plena floração); Estádio 7 (frutificação - ervilha); Estádio 8 (início da maturação - plena maturação); Estádio 9 (início da queda das folhas queda das folhas). * representa diferença significativa entre os ciclos ao nível de 5\%, pelo teste de Tukey. 


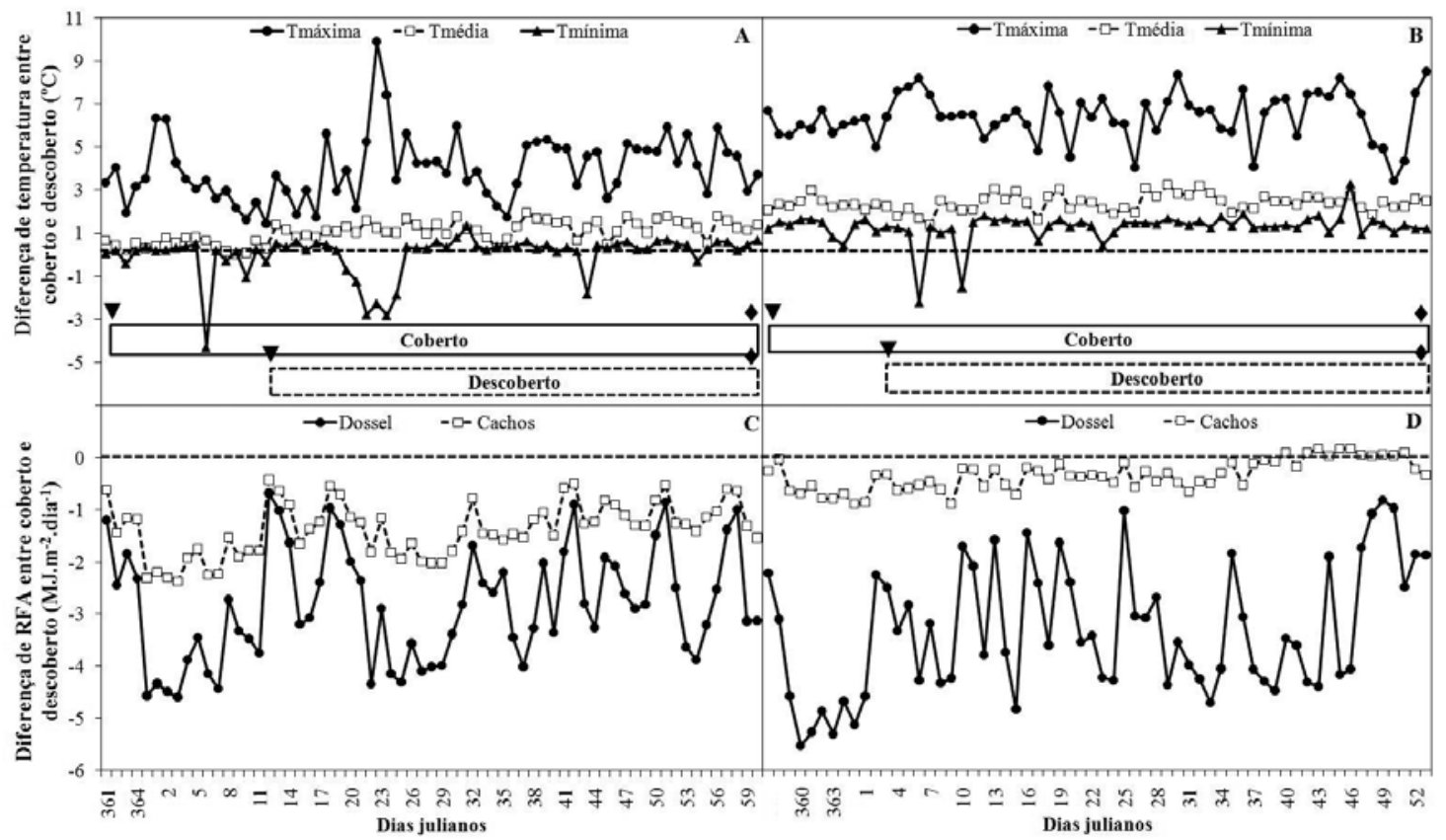

FIGURA 2- Diferença entre as temperaturas máxima, média e mínima (A- ciclo de 2005/2006 e B - 2006/2007) e a diferença de radiação fotossinteticamente ativa incidente no dossel e nos cachos $(\mathrm{C}$ - ciclo de 2005/2006 e D - 2006/2007), no período de mudança de cor até a colheita em vinhedo da cultivar Moscato Giallo, conduzida em "Y", com cobertura plástica e descoberta, nos ciclos de 2005/2006 e 2006/2007. Flores da Cunha-RS. As barras horizontais representam o período de início a fim de maturação das uvas cobertas e descobertas.

\section{CONCLUSÃO}

A cobertura plástica aumentou o somatório térmico e, com isto, antecipou o início da brotação e reduziu a duração das etapas fenológicas até a mudança de cor das bagas. Entretanto, a redução da radiação fotossinteticamente ativa, proporcionada pela cobertura plástica, atrasou o processo de maturação das uvas da cultivar Moscato Giallo, nas condições climáticas da Serra Gaúcha.

\section{REFERÊNCIAS}

ANTONACCI, D. Comportamento produttivo di nove cultivar di uve da tavola coltivata in ambiente protetto. Vignevini, Roma, v.20, n.1-2, p.53-62. 1993.

CHAVARRIA, G.; SANTOS, H.P.; FELIPPETO, J.; MARODIN, G.A.B.; BERGAMASCHI, H.; CARDOSO, L. Effet de la couverture plastique sur la croissance et sur le métabolisme de la vigne. In: CONGRESSODECLIMAEVITICULTURA, 1., 2007a, Zaragoza. Anais... p. 59-64.
CHAVARRIA, G.; SANTOS, H.P.; SÔNEGO, O.R.; MARODIN, G.A.B.; BERGAMASCHI, H.; CARDOSO, L. Incidência de doenças e necessidade de controle em cultivo protegido de videira. Revista Brasileira de Fruticultura, Jaboticabal, v.29, n.3, p.477-482, $2007 b$.

COUVILLON, G.A. ; EREZ, A. Effect of level and duration of high temperatures on rest in the peach. Journal of the American Society for Horticultural Science, Geneva, v.110, n.4, p. 579-581, 1985.

JACKSON R.S. Wine Science: principles, practices, perception. $2^{\text {nd }}$ ed. San Diego: Academic Press, 2000. $654 \mathrm{p}$.

LEÃO, P.C. de S.; DA SILVA, E.E.G. Caracterização fenológica e requerimentos térmicos de variedades de uvas sem sementes no vale do São Francisco, Revista Brasileira de Fruticultura, Jaboticabal, v.25, n.3, p.379-382, 2003.

LORENZ, D.H.; EICHORN, K.W.; BLEHOLDER, H., KLOSE, R.; MEIER, U.; WEBER, E. Phenological growth stages of grapevine (Vitis vinifera L.) - Codes and descriptions according to the extended $\mathrm{BBCH}$ 
scale. Autralian Journal of Grape and Wine Research, Glen Usmond, v.1, p.100-103, 1995.

MANDELLI, F. Comportamento fenológico das principais cultivares de Vitis vinifera $\mathbf{L}$. para a região de Bento Gonçalves-RS. 1984. $125 \mathrm{f}$. Dissertação (Mestrado em Agrometeorologia) Escola Superior de Agricultura "Luiz de Queiroz", Universidade de São Paulo, Piracicaba, 1984.

MANDELLI, F. Relações entre variáveis meterológicas, fenologia e qualidade da uva na "Serra Gaúcha" 2002. 196 f. Tese (Doutorado em Fitotecnia) - Universidade Federal do Rio Grande do Sul, Faculdade de Agronomia, Porto Alegre, 2002.

MULLINS M.G.; BOUQUET A.; WILLIAMS L.E. Biology of the grapevine. New York: Cambridge University, 1992.239p.

PALCHETTI, C.; GOZZINI, B.; MIGLIETTA, F. The effect of trainning system and cultivar on the rate of leaf appearance of the grapevine (Vitis vinifera L.). Journal International des Sciences de la Vigne et du Vin, Bordeaux, v.29, n.2, p.69-74.1995.

R. Development Core Team. R: A language and environment for statistical computing. $R$. Foundation for statistical computing. Vienna, Austria. Disponível em: <http://www.r-project.org/>. Acesso em: 01 dez. 2007.

RANA, G.; KATERJI, N.; INTRONA, M.; HAMMAMI, A. Microclimate and plant water relationship of the "overhead" table grape vineyard maneged with three different covering techniques. Scientia Horticulturae, Amsterdam, n.102, p.105-120, 2004.
SANTOS, C.E.; ROBERTO, S.R.; SATO, A.J.; JUBILEU, B.S. Caracterização da fenologia e da demanda térmica das videiras 'Cabernet Sauvignon' e 'Tannat' para a região norte do Paraná. Acta Scientiarum, Maringá, v.29, n.3, p.361-366, 2007.

SCHIEDECK, G. Ecofisiologia da videira e qualidade da uva Niágara Rosada conduzida sob estufa plástica. 1996. 111 f. Dissertação (Mestrado em Fitotecnia) Universidade Federal do Rio Grande do Sul, Porto Alegre, 1996.

SMART, R.; ROBINSON, M. Sun light into wine: a handbook for winegrape canopy management. Adelaide: Winetitles, 1985. 88p.

TERRA, M.M.; PIRES, E.J.P.; POMMER, C.V. Tecnologia para a produção de uva Itália na região noroeste do Estado de São Paulo. 2.ed. Campinas: CATI, 1998. 58p. (Documento Técnico, 97).

VILLA NOVA, N. A.; PEDRO JUNIOR, M. J.; PEREIRA, A. R.; OMETTO, J. C. Estimativa de grausdia acumulados acima de qualquer temperaturabase, em função das temperaturas máxima e mínima. São Paulo: Universidade de São Paulo, Instituto de Geografia, 1972. 8p. (Caderno de Ciências da Terra, 30).

WESTPHALEN, S.L. Bases ecológicas para determinação de regiões de maior aptidão vitícola no Rio Grande de Sul. Montevideo: Ministério de Industria y Energia. Laboratório Tecnológico de Uruguay, 1977. p.89-101. (Cuaderno Técnico, 38). 